\title{
DIALEKTIKA KEAGAMAAN DAN KEBANGSAAN DALAM TAREKAT SHIDDIQIYYAH
}

\author{
DIALECTICS OF RELIGION AND NATION IN THE TAREKAT SHIDDIQIYYAH \\ Ahmad Munjin Nasih*, Meidi Saputra \\ Universitas Negeri Malang \\ Jalan Semarang Nomor 5 Malang 65145, Indonesia \\ Tasmuji, Abd. Syakur \\ Universitas Islam Negeri Sunan Ampel Surabaya \\ Jalan Ahmad Yani Nomor 117 Surabaya 60237, Indonesia
}

\section{INFO ARTIKEL}

\section{Riwayat Artikel: \\ Diterima : 25 Februari 2021 \\ Disetujui : 30 Mei 2021}

\section{Keywords:}

religion, nationality, state,

tarekat shiddiqiyah

\section{Kata Kunci:}

agama, kebangsaan, negara, tarekat shiddiqiyah

\section{*) Korespondensi:}

E-mail: munjin.nasih.fs@um.ac.id

\begin{abstract}
: the purpose of this study was to describe the history of the Shiddiqiyyah Tarekat, the forms of nationalism in the Shiddiqiyyah Tarekat, and the meeting point of religion and nationalism in the Shiddiqiyyah Tarekat. The research approach used a qualitative approach with a descriptive research type. The data collection techniques used were observation, in-depth interviews, and literature study. The results showed that the Shiddiqiyyah Tarekat was a tarekat with very rapid development and had its own uniqueness that was different from other Sufi groups or tarekat. The forms of nationalism of the shiddiqiyyah tarekat were the eight abilities that must be held, the national monument, the poetry of the source of the independence of the Indonesian nation and the establishment of the Unitary State of the Republic of Indonesia and the establishment of a brotherhood of love for the Indonesian homeland. The meeting point of religion and nationalism in the shiddiqiyyah tarekat was the concept of hubbul wathan minal iman, which means that love for the country was part of faith.
\end{abstract}

\begin{abstract}
Abstrak: tujuan kajian ini yaitu untuk mendeskripsikan sejarah Tarekat Shiddiqiyyah, bentuk-bentuk nasionalisme Tarekat Shiddiqiyyah dan titik temu agama dan nasionalisme dalam Tarekat Shiddiqiyyah. Pendekatan kajian yang digunakan yaitu pendekatan kualitatif dengan jenis penelitian deskriptif. Teknik pengumpulan data yang digunakan yaitu observasi, wawancara mendalam dan studi kepustakaan. Hasil penelitian diperoleh bahwa Tarekat Shiddiqiyyah merupakan tarekat dengan perkembangan yang sangat pesat dan mempunyai kekhasan tersendiri yang berbeda dengan kelompok sufi atau tarekat yang lain. Bentuk-bentuk nasionalisme tarekat shiddiqiyyah yaitu delapan kesanggupan yang harus dipegang, monumen kebangsaan, syair sumber kemerdekaan Bangsa Indonesia dan berdirinya Negara Kesatuan Republik Indonesia serta pendirian persaudaraan cinta tanah air Indonesia. Titik temu agama dan nasionalisme dalam Tarekat Shiddiqiyyah yaitu adanya konsep hubbul wathan minal iman yang berarti cinta tanah air adalah sebagian dari iman.
\end{abstract}

\section{PENDAHULUAN}

Diskursus tentang relasi agama dan negara selalu menarik untuk diangkat ke permukaan. Pada awal perjalanan bangsa Indonesia, relasi agama dan negara menjadi poin pembahasan yang sangat krusial untuk menentukan bagaimana bentuk sistem ketatanegaraan Indonesia dibangun. Perdebatan keras terjadi antara tokoh agama, khususnya dari kalangan muslim, dan tokoh nasionalis. Kelompok Islam menghendaki agar negara Indonesia dikelola dengan sistem Islam, sementara kelompok nasionalis dengan tegas 
menolak gagasan ini dengan pertimbangan kebhinekaan yang ada di Indonesia (Wahid, 2011). Jalan tengah akhirnya ditempuh untuk mengakhiri perdebatan dengan tidak menjadikan agama sebagai landasan formal tetapi nilai-nilai agama tetap menjadi sumber inspirasi dalam kehidupan berbangsa dan bernegara (Jailani, 2015). Jalan tengah yang disepakati di antara para tokoh tidak sepenuhnya bisa diterima oleh sebagian umat Islam.

Munculnya disintegrasi bangsa akhirnya tidak bisa dihindari. Upaya pemberontakan dan pemisahan diri dari NKRI menurut Supyan (2016) dilakukan oleh para tokoh yang tidak sependapat dengan jalan tengah. Hal yang dilakukan yaitu dengan mendirikan Negara Islam Indonesia (NII) dan pemberontakan Kahar Muzakkar (Azizah, 2019). Sistem negara dengan tatanan demokrasinya dianggap menyimpang dari ajaran Islam (Zaprulkhan, 2014). Sekalipun para pemberontak dapat ditumpas, namun ideologi yang terpatri dalam jiwa mereka terus berkembang dan berevolusi sampai generasi berikutnya. Terlebih ketika ideologi ini bertemu dengan ideologi transnasionalis yang mengusung simbol-simbol agama seperti Ikhwanul Muslimin dan Hizbut Tahrir, semangat yang sempat terpendam menemukan momentum untuk bangkit kembali (Arif, 2016). Hal yang berkaitan dengan negara dan agama menjadi polemik yang tidak bisa dihilangkan.

Para tokoh dari kalangan Nahdlatul Ulama (NU) dan pesantren merupakan bagian dari kelompok yang sependapat dengan jalan tengah. Tidak heran apabila sejak awal kemerdekaan sampai saat ini, komitmen NU dan pesantren untuk mempertahankan keutuhan bangsa dan NKRI selalu dikedepankan. Pendirian Laskar Hisbullah oleh kalangan santri pada masa menjelang kemerdekaan dan lahirnya resolusi jihad yang diprakarsai oleh tokoh utama NU KH. Hasyim Asy'ari pada tanggal 22 Oktober 1945 merupakan bukti nyata bagaimana komitmen NU dan pesantren terhadap bangsa dan negara. Penerimaan NU terhadap Pancasila sebagai asas tunggal organisasi pada tahun 1984. Komitmen pesantren dalam mengawal NKRI akhirnya mendapatkan pengakuan dari pemerintah dengan keluarnya Keputusan Presiden Nomor 22 Tahun 2015 yang ditetapkan pada tanggal 22 Oktober sebagai Hari Santri.
Komitmen kebangsaan dari kalangan pesantren bisa dilihat di lingkungan pesantren. Pesantren merupakan pusat pengembangan Tarekat Shiddiqiyyah yang secara tegas menampilkan sisi nasionalisme dalam misi pendidikan dan dakwahnya. Salah satunya tarekat mu'tabarah yang dalam tiga dekade belakangan, menarik perhatian para akademisi dan pemerhati kajian sufistik di Indonesia. Tarekat ini dalam rentang waktu yang cukup singkat dapat berkembang cukup pesat dengan jumlah pengikut yang sangat banyak (Munir, 2012). Pesantren menjadi wadah dalam mengembangkan ajaran Tarekat Shiddiqiyyah.

Sebagai bagian tak terpisahkan dari dunia tasawuf, kelompok tarekat pada umumnya lebih banyak berkonsentrasi kepada aspek personal bagaimana memperbaiki hati dan perilaku dalam rangka beribadah kepada Allah dibanding mengurusi hal-hal yang berkaitan dengan keduniawian. Tampilan sisi nasionalisme dari pesantren yang berfokus pada ketarekatan menjadi daya tarik tersendiri. Sebagaimana tarekat mu'tabarah lainnya, tarekat Shiddiqiyyah mengajarkan ajaran-ajaran tasawuf kepada para pengikutnya. Namun ada hal yang berbeda dan unik dari tarekat ini, yakni ajaran tentang pentingnya nasionalisme atau cinta tanah air bagi pengikutnya. Ajaran tentang cinta tanah air dalam dunia tasawuf merupakan bentuk paham nasionalisme bukan menjadi objek yang cukup penting bahkan hampir tidak tersentuh sama sekali. Paham atau ajaran nasionalisme selama ini dianggap sebagai persoalan yang bersifat duniawi belaka, sehingga nasionalisme yang di dalamnya memuat ajaran cinta tanah air dianggap justru dapat menjauhkan hati nurani manusia dari Tuhannya.

Sederet kegiatan Tarekat Shiddiqiyah memperlihatkan ajaran tentang nasionalisme. Fakta ini menarik untuk ditelusuri bagaimana konsep Tarekat Shiddiqiyah memposisikan bangunan nation state dalam kerangka misi dakwahnya. Sebab sebagai bagian dari kelompok tasawuf, pola menyatukan nilai agama dan kebangsaan menjadi sesuatu yang tidak lazim (Tasmuji, 2019). Keunikan dari Tarekat Shiddiqiyyah adalah mampu menciptakan kesadaran kebangsaan (national consciousness) yang relatif tinggi bagi para pengikutnya. Tarekat ini berbeda dan bukan menjadi concern dari tarekat yang lainnya (Syakur, 
2008). Fenomena menunjukkan bahwa tarekat ini memiliki keunikan tersendiri, khususnya dari aspek ajaran-ajaran dan pandangannya terhadap kehidupan dunia, yang memang berbeda dengan tarekat-tarekat lain (Munir, 2012). Nilai nasionalisme yang diajarkan dalam Tarekat Shiddiqiyyah dapat bersatu dengan nilai agama.

Tulisan ini mencoba untuk menelusuri berbagai hal yang dilakukan Tarekat Shiddiqiyah terkait pengembangan nasionalisme di lingkungan pesantren. Melihat banyak bermunculan gerakan untuk mempertentangkan antara agama, negara dan demokrasi. Sebagian kelompok kecil dalam Islam bahkan berpendapat bahwa tatanan negara harus selaras dengan tatanan kepemimpinan. Berdasarkan permasalahan tersebut, artikel ini akan membahas mengenai (1) sejarah tarekat shiddiqiyyah, (2) bentuk-bentuk nasionalisme tarekat shiddiqiyyah, dan (3) titik temu agama dan nasionalisme dalam tarekat shiddiqiyyah.

\section{METODE}

Pendekatan penelitian yang digunakan yaitu pendekatan kualitatif dengan jenis penelitian deskriptif. Sumber data dikategorikan dalam data primer dan sekunder. Penelitian deskriptif kualitatif ditujukan untuk mendeskripsikan dan menggambarkan fenomena-fenomena yang ada (Sukmadinata, 2011). Teknik pengumpulan data dilakukan dengan beberapa cara yaitu observasi dan wawancara mendalam. Pengamatan dilakukan dengan melakukan observasi langsung dengan mengunjungi pesantren Majmaal Bahrain sebagai pusat penyebaran Tarekat Shiddiqiyyah untuk melihat situasi, kondisi, dan berbagai aktivitas yang terjadi di pesantren. Wawancara mendalam dilakukan dengan pengurus Pesantren Tarekat Shiddiqiyyah, para santri dan jamaah Tarekat Shiddiqiyyah. Untuk menyajikan temuan data yang representatif dan memadai, data yang sudah dikumpulkan dianalisis dengan menggunakan triangulasi data dan telaah terhadap berbagai dokumen yang relevan.

\section{HASIL DAN PEMBAHASAN}

\section{Sejarah Tarekat Shiddiqiyah}

Pengertian tarekat dari sisi bahasa Arab yakni thariqah yang berarti jalan atau metode. Makna jalan yang dimaksud adalah panduan doktrin dan ritual khusus yang dilakukan oleh orang-orang sufi. Adapun dari sisi istilah yaitu bagian dari ilmu tasawuf sebagai proses penguatan nilai spiritual. Tujuan tarekat menurut (Tedy, 2018) yaitu untuk mengimplementasikan peraturan-peraturan syariat Islam yang sah dengan menekankan nilai-nilai moralitas yang baik (al-akhlak al-karimah). Tarekat dilakukan melalui zikir serta kegiatan mengamalkan ritual keagamaan dengan menjalankan wirid- wirid tertentu sebagai pendekatan kepada Allah (Turmudi, 2004). Selain dari pengertian tersebut, tarekat juga diartikan sebagai institusi yang mengorganisasikan orang-orang sufi dalam mengamalkan doktrin dan ritual khususnya. Makna tarekat sebagai institusi lebih populer di kalangan masyarakat dibanding sebagai jalan atau metode (Dhofier, 1994). Tarekat sebagai petunjuk atau jalan dalam melakukan ibadah untuk mendekatkan diri dengan Allah.

Pada masa awal perkembangannya, tarekat hanya sebatas perkumpulan biasa yang tidak terorganisir secara sistematis. Seiring berjalannya waktu dan dinamika, tarekat berevolusi menjadi organisasi yang dikelola secara terstruktur karena semakin banyak pengikutnya. Di Indonesia organisasi tarekat berhimpun dalam satu wadah yang dinamakan Jam 'iyyah Ahlith Thariqah alMu'tabarah yang berarti perkumpulan pengamal tarekat yang diakui. Perkumpulan ini pertama kali dideklarasikan pada tanggal 10 Oktober 1957 di Magelang, Jawa Tengah. Pendirian ini bertujuan untuk memayungi semua tarekat yang digolongkan sebagai tarekat muktabarah. Pada tahun 1979 terjadi dinamika politik yang mengakibatkan perpecahan tarekat menjadi dua organisasi, yakni Jam 'iyyah Ahli ath-Thariqah al-Mu'tabarah Indonesia (JATMI) dan Jam'iyyah Ahli ath-Thariqah al-Mu'tabarah an-Nadhliyyah (JATMAN). Tarekat Shiddiqiyyah adalah salah satu tarekat yang dinilai mu'tabarah (diakui/sah) di Indonesia berdasarkan keputusan JATMI tahun 2009. Pengakuan sebagai tarekat mu'tabarah ini merupakan revisi dari keputusan sebelumnya yang menyatakan bahwa tarekat Shiddiqiyyah termasuk tarekat ghairu mu'tabarah (tidak diakui/tidak sah). Bahkan dari 40 tarekat yang dinyatakan sebagai mu'tabarah, nama tarekat Shiddiqiyah berada pada nomor urut dua.

Tarekat Shiddiqiyyah diperkenalkan di Indonesia oleh Kyai Muhammad Muchtar bin $\mathrm{H}$. Abdul Mu'thi. Pengenalan Kyai Muchtar terhadap tarekat Shiddiqiyah bermula dari pertemuan Kyai Muchtar dengan Syekh Syueb Jamali alBantani seorang mursyid tarekat Khalwatiyah 
pada tahun 1952 di Masjid Agung Banten. Dari pertemuan pertama kemudian berlanjut dengan pertemuan-pertemuan berikutnya, sampai akhirnya Kyai Muchtar mantap untuk berbaiat tarekat Khalwatiyah dan menjadi murid Syekh Syueb (Nasih, 2016). Tarekat Khalwatiyah bukanlah satu-satunya tarekat yang dipelajari oleh Kyai Muchtar, ada tarekat-tarekat lain yang pernah beliau pelajari, seperti tarekat Naqsyabandiyah, Anfasiyah, Akmaliyah, dan Nariyah. Hanya saja dalam perjalanannya Kyai Muchtar berketetapan hati memilih untuk mengajarkan tarekat Khalwatiyah (Shiddiqiyyah) kepada masyarakat sampai saat ini (A'dham, 2011). Paham ini baik dikembangkan untuk mendidik manusia menjadi orang-orang yang Shiddiqiyyah.

Tarekat Shiddiqiyah berbeda dengan tarekat pada umumnya yang dilabeli nama sesuai mursyid atau pemimpinnya. Tarekat ini tidak menyebut dirinya tarekat Mu'thiyyah ataupun Muchtariyyah, sebagai dampak penisbahan kepada Kyai Muhammad Muchtar Mu'thi sebagai seorang mursyid, tetapi tetap menggunakan sebutan Șiddiqiyyah (Syakur, 2008). Hal ini dilakukan Kyai Muchtar untuk memenuhi keinginan sang guru (Syekh Syueb) agar nama tarekat yang dipelajari dikembalikan kepada nama awalnya. Kemunculan nama Shiddiqiyyah sebenarnya merupakan amanat dari Syekh Syueb kepada Kyai Muchtar. Sebab menurut Syeikh Syueb dari sisi sejarah nama Khalwatiyah bukanlah nama awal dari tarekat tersebut, nama awalnya adalah Shiddiqiyyah. Oleh karenanya, Kyai Muchtar diberikan amanat untuk mengembalikan pada nama asalnya apabila di kemudian hari mampu melakukannya. Untuk alasan ini, Syeikh Syueb meminta Kyai Muchtar menelaah kitab tasawuf Tanwirul qulub fi mu'amalati allamil ghuyub, karya Syeikh Najmuddin al Kurdi, seorang tokoh tarekat Naqsyabandiyah. Dalam kitab tersebut dijelaskan silsilah tarekat Khalwatiyah berikut sejarah perubahan nama-namanya. Perubahan nama dari Tarekat Khalwatiyah menjadi Tarekat Shiddiqiyyah dilakukan kyai Muchtar karena semata-mata menjalankan perintah gurunya.

Perjuangan untuk mengembalikan nama Shiddiqiyyah sebagaimana diamanatkan Syekh Syueb tidak dilakukan secara langsung, namun ada beberapa tahapan yang dilakukan oleh Kyai Muchtar. Pada tahun 1960 Kyai Muchtar menamakan ajarannya dengan sebutan Ilmu Haq
Layar Tujuh Pati. Kemudian pada tahun 1963 diubah menjadi Ilmu Haq Shiddiqiyyah, dan pada tahun 1967 diubah lagi menjadi Tarekat Khalwatiyah Shiddiqiyyah. Terakhir pada tahun 1972 disederhanakan menjadi Tarekat Shiddiqiyyah (Pranoto, 2015). Untuk membantu menyampaikan ajaran tarekat Shiddiqiyyah, Kyai Muchtar mengangkat beberapa murid khusus yang telah berbaiat untuk menjadi khalifah (wakil) dari mursyid. Sampai pada tahun 1973, guna mengembangkan pengajaran tarekat ini, Kyai Muchtar mendirikan Yayasan Pendidikan Shiddiqiyyah (YPS). Melalui yayasan tersebut, Tarekat Shiddiqiyyah mampu berkembang dan eksis sampai ke penjuru Indonesia bahkan ke manca negara serta mampu memberikan ruang kesejukan bagi masyarakat (Shodiq, 2016). Untuk mempermudah penyebaran ajarannya, diangkatlah murid-murid menjadi khalifah yang bertugas menjadi membantu mursyid terkait dengan pengajaran dan pendidikan Shiddiqiyyah.

Tarekat Shiddiqiyyah adalah organisasi keagamaan Islam. Tujuan dari tarekat ini yaitu untuk mendidik, membimbing, dan menuntun manusia agar (1) dekat kepada Allah yang sebenar-benarnya melalui praktik dzikir Jahar nafi itsbat, (2) kenal kepada Allah yang sebenarbenarnya kenal melalui praktik dzikir Sirri ismu dzat, (3)menjadi manusia taqwallah, taqwa yang sebenar-benarnya taqwa melalui jalan shalat, puasa, dan dzikir kalimat taqwa, dan (4) menjadi manusia yang bersyukur kepada Allah (Pranoto, 2015). Diharapkan dengan ajaran yang sudah diberikan, dapat mendekatkan diri kepada Allah melalui jalan tasawuf.

Pada tahun 2001, Tarekat Shiddiqiyyah membentuk lembaga kemanusiaan yang bernama Dhilal Berkat Rahmat Allah (Dibra). Lembaga ini mengelola unit bantuan sosial kemanusiaan yang dihimpun dari seluruh warga Shiddiqiyyah. Salah satu program unggulan Dibra adalah pembangunan Rumah Layak Huni (RLH) yang diperuntukkan kepada warga Shiddiqiyyah dan masyarakat umum. Selain itu, Dibra juga mengembangkan model tabungan sosial Tajrin Naf'ah. Keuntungan dari pengelolaan tabungan disalurkan untuk para duafa' di lingkungan pesantren dan memberi beasiswa kepada para santri. Berbeda dengan pemahaman tasawuf dan tarekat pada umumnya yang cenderung fatalisme, Tarekat Shiddiqiyah mampu meramu ajaran tasawuf dengan semangat berwirausaha 
(Munir, 2012). Beberapa unit usaha yang dibentuk diantaranya, hotel bintang, produksi air mineral kemasan, mitra usaha sigaret kretek, perusahaan rokok, klinik kesehatan, produksi madu, kerajinan tangan dan rumah makan.

\section{Bentuk-bentuk Nasionalisme Tarekat Shiddiqiyyah}

Nasionalisme tarekat shiddiqiyyah terdiri atas empat bentuk yaitu (1) delapan kesanggupan, (2) monumen kebangsaan, (3) syair sumber kemerdekaan Bangsa Indonesia dan berdirinya Negara Kesatuan Republik Indonesia, serta (4) pendirian persaudaraan cinta tanah air Indonesia. Konsep nasionalisme yang pertama dalam tarekat Shiddiqiyyah adalah rumus syarat masuk tarekat Shiddiqiyyah. Rumusan ini sering juga disebut dengan "delapan kesanggupan" yang menjadi prasyarat bagi siapa saja yang tertarik masuk dalam tarekat ini. Rumusan ini berisi delapan poin kesanggupan yang harus dipegang teguh oleh murid-murid tarekat, antara lain (1) sanggup bakti kepada Allah Ta'ala, (2) sanggup bakti kepada Rosulullah, (3) sanggup bakti kepada orang tua, (4) sanggup bakti kepada sesama manusia, (5) sanggup bakti kepada Negara Republik Indonesia, (6) sanggup cinta kepada tanah air Indonesia, (7) sanggup mengamalkan thoriqoh shiddiqiyyah, dan (8) sanggup menghargai waktu dari delapan kesanggupan tersebut.

Secara eksplisit nilai-nilai nasionalisme tertuang dalam butir lima dan enam yaitu kesanggupan berbakti kepada NKRI dan mencintai tanah air Indonesia. Bagi tarekat Shiddiqiyyah bakti kepada NKRI dan kecintaan kepada tanah air adalah dua hal yang sangat penting, setelah berbakti kepada Allah, Rasul, orang tua, dan sesama manusia. Kyai Muchtar Mu'thi sebagai mursyid tarekat ini menyatakan bahwa bakti kepada negara Republik Indonesia merupakan bentuk syukur warga negara atas karunia Allah. Delapan kesanggupan ini tidak hanya menjadi dokumen yang harus dibaca pada awal masuk tarekat, tetapi para pengikut harus tetap membacanya ketika sudah masuk. Biasanya pada acara-acara resmi ketarekatan, delapan kesanggupan ini dibaca secara bersama-sama yang diharapkan bisa merawat komitmen yang pernah dijanjikan agar tidak cepat memudar. Bahkan untuk mengingatkan hal ini setiap waktu, dibangun monumen delapan kesanggupan.
Pusat kajian dan pengajaran Tarekat Shiddiqiyyah memiliki puluhan monumen yang dibangun di lingkungan pesantren. Secara umum monumen yang dibangun bertema agama, lebih khusus lagi yang berkaitan dengan ajaran tasawuf. Ada hal yang menarik dari sekian monumen yang dibangun, yakni beberapa diantaranya bertema nilai-nilai kebangsaan. Setidaknya ada tujuh bangunan monumen bertema kebangsaan yang dibangun di lingkungan pesantren, yakni (1) hubbul wathon minal iman (cinta tanah air sebagian dari iman), (2) Proklamasi, (3) Pancasila, (4) Sumpah Pemuda, (5) lagu kebangsaan Indonesia Raya, (6) Pembukaan UUD 1945, dan (7) wasiat WR Supratman. Adapun penempatan lokasi monumen menyebar di berbagai sudut pesantren, dengan ukuran bangunan dan desain yang bervariasi.

Pemilihan tema-tema dalam pembangunan monumen sengaja diambilkan dari nilai-nilai penting yang mampu menggambarkan suasana kebatinan bangsa Indonesia dalam proses kemerdekaannya. Tujuan dibangunnya monumen kebangsaan diharapkan mampu menumbuhkan rasa syukur kepada Allah atas limpahan nikmat kemerdekaan kepada tanah air Indonesia serta sebagai realisasi rasa terima kasih kepada para pahlawan bangsa dan pejuang kemerdekaan Indonesia. Monumen-monumen kebangsaan juga merupakan media pendidikan cinta tanah air Indonesia bagi generasi muda sebagai penerus bangsa (Abdullah, 2017). Monumen yang didirikan di lingkungan pesantren menjadi media untuk menumbuhkan rasa nasionalisme.

Nilai-nilai nasionalisme dalam Tarekat Shiddiqiyyah dapat terlihat pada penyusunan syair sumber kemerdekaan bangsa Indonesia dan berdirinya NKRI. Syair ini disusun sendiri oleh mursyid tarekat Kyai Muchtar Mu'thi yang terdiri dari 12 bait dan dibaca berulang sebanyak dua kali. Pembacaan syair biasanya dilakukan secara bersama-sama dalam seremoni kegiatan-kegiatan ketarekatan. Untuk acaraacara tertentu syair ini dibaca setelah lagu kebangsaan Indonesia Raya dikumandangkan. Secara umum komposisi lirik syair terdiri dari dua bagian penting yaitu (1) bagian yang berbicara tentang pentingnya mengingat akan rahmat Allah dalam proses kemerdekaan bangsa Indonesia dan berdirinya NKRI, dan (2) ajakan untuk mensyukuri kemerdekaan tersebut. Syair ini bertujuan untuk mengingatkan kepada 
seluruh pengikut Tarekat Shiddiqiyyah dan menumbuhkan kesadaran dalam diri mereka bahwa kemerdekaan bangsa Indonesia dan berdirinya NKRI adalah anugerah dari Allah. Melalui syair ini Kyai Muchtar mencoba menggabungkan aspek sakral dan profan dalam memaknai arti kemerdekaan (Tasmuji, 2019). Kyai Muchtar menyakini bahwa capaian kemerdekaan bukan hanya urusan profan dimana bangsa Indonesia harus berjuang sampai tetes darah penghabisan, namun lebih dari itu kemerdekaan merupakan berkat dan rahmat Allah.

Lirik dari syair sumber kemerdekaan bangsa Indonesia dan berdirinya NKRI memilik daya tarik atau ciri khas yakni pemilihan diksi yang menunjukkan adanya perbedaan. Bagi Shiddiqiyyah kemerdekaan bangsa Indonesia dan berdirinya NKRI mempunyai dimensi waktu yang berbeda yaitu pada tanggal 17 Agustus 1945 diyakini sebagai hari Kemerdekaan bangsa Indonesia, sementara tanggal 18 Agustus 1945 merupakan hari berdirinya negara RI. Berbeda dengan pandangan kebanyakan warga Indonesia bahwa tanggal 17 Agustus 1945 merupakan hari kemerdekaan bangsa Indonesia sekaligus berdirinya Republik Indonesia.

Bentuk nasionalisme Indonesia yang keempat tampak pada pendirian PCTAI. Pada awal tahun 2006 Kyai Muchtar Mu'thi sebagai mursyid Tarekat Shiddiqiyah melontarkan ide untuk menyelenggarakan seminar warisan Empu Tantular yakni kitab "Sutasoma". Kitab tersebut sebagai warisan leluhur yang di dalamnya terdapat konsep "Bhinneka Tunggal Ika" yang berarti berbedabeda tetapi tetap satu jua. Kemudian prakasa itu ditindaklanjuti oleh pesantren Shiddiqiyyah dengan menyelenggarakan seminar nasional bertajuk "Sutasoma dalam Konteks Peningkatan Cinta Tanah Air". Setelah pelaksanaan seminar nasional, muncul ide mendirikan satu organisasi yang bisa mengawal ide besar menanamkan cinta kepada tanah air Indonesia. Akhirnya pada tanggal 21 Maret 2010 didirikanlah organisasi Persaudaraan Cinta Tanah Air Indonesia (PCTAI). Pendeklarasian organisasi tersebut dihadiri kurang lebih sekitar 10.000 orang dengan pagelaran seni budaya. Pendirian PCTAI diharapkan bisa membangkitkan kembali rasa cinta tanah air bangsa Indonesia melalui seni, budaya, pendidikan dan pemberdayaan ekonomi menuju kesejahteraan bangsa Indonesia. Visi PCTAI adalah terwujudnya bangsa Indonesia yang cinta tanah air. Adapun misi PCTAI untuk mewujudkan visi tersebut yaitu: (a) menanamkan cinta tanah air indonesia sebagai bagian dari iman, (b) menyelenggarakan pendidikan cinta tanah air dalam arti yang seluas-luasnya, (c) melestarikan nilai-nilai cinta tanah air Indonesia, dan (d) melestarikan nilai-nilai luhur budaya bangsa.

Tujuan berdirinya organisasi PCTAI adalah untuk: (a) mewujudkan kesadaran, kebersamaan, dan persatuan-kesatuan bangsa Indonesia, (b) menjadikan manusia Indonesia yang bersyukur kepada Tuhan Yang Maha dalam Negara Kesatuan Republik Indonesia, (c) menumbuhkan rasa cinta dan bersedia membela Tanah Air Indonesia demi terpeliharanya kelangsungan hidup bangsa dan negara, dan d)melestarikan nilai-nilai luhur terhadap keragaman budaya bangsa sebagai Rahmat dari Tuhan Yang Maha Kuasa (Abdullah, 2017). Sesuai dengan Anggaran Dasar dan Anggaran Rumah Tangga (AD/ART)organisasi, PCTAI dinyatakan sebagai organisasi non politik dan tidak berafiliasi dengan organisasi politik apapun dan manapun. Struktur organisasi PCTAI dirancang berjenjang mulai dari pusat sampai daerah dan perwakilan luar negeri.

\section{Titik Temu Agama dan Nasionalisme dalam Tarekat Shiddiqiyah}

Tarekat Shiddiqiyyah berkembang sangat pesat di Indonesia. Sampai saat ini tarekat Shiddiqiyyah memiliki perwakilan di 24 provinsi dan 141 kabupaten/kota di seluruh Indonesia dengan pengikut diperkirakan mencapai jutaan orang. Lokasi pusat pengembangan ketarekatan ada yang berada di suatu desa kecil, namun hal ini tidak mengurangi antusiasme masyarakat muslim dari seluruh penjuru negeri untuk bergabung dan belajar agama Islam melalui tarekat ini. Salah satu daya tarik dari tarekat Shiddiqiyyah adalah ajaran tentang manunggalnya keimanan dan kemanusiaan. Ajaran ini berarti bahwa seorang muslim harus mampu mewujudkan keseimbangan antara urusan duniawi dan ukhrawi. Keduanya harus berjalan beriringan dan saling mengisi. Ajaran ini, dari perspektif dunia sufistik bisa dikatakan tidak populer, sebab kelompok sufi seringkali memberikan porsi ukhrawi lebih banyak dibanding urusan duniawi. Artinya Tarekat Shiddiqiyah disamping mengajarkan kepada para pengikutnya bagaimana menjalankan kewajiban agama dan praktik ketarekatan, juga mendorong agar senantiasa melakukan amal- 
amal sosial, peningkatan sektor ekonomi, juga pemberdayaan masyarakat sebagai bagian dari urusan kemanusiaan.

Tarekat Shiddiqiyyah juga mengajarkan akan pentingnya nasionalisme bagi seluruh warga. Nasionalisme bukan saja sebagai sikap positif yang seharusnya dimiliki oleh warga negara, tetapi lebih dari itu nasionalisme merupakan bagian dari perintah agama. Dalam konteks nasionalisme, Tarekat Shiddiqiyyah mendasarkan ajarannya dari suatu kaidah yang diyakininya sebagai hadis yakni hubbul wathon minal iman yang berarti cinta tanah air adalah sebagian dari iman. Dari kaidah inilah Tarekat Shiddiqiyyah mengembangkan berbagai kegiatan dan atribut ketarekatan sebagai perwujudan nasionalisme bagi seluruh warganya. Keberadaan kaidah hubbul wathon minal iman, dalam kajian keislaman memang masih mengundang perdebatan, antara hadits Nabi atau ungkapan bijak dari para ulama. Apabila ditelisik jauh lebih dalam, konsep hubbul wathan minal iman adalah pemikiran para ulama Nahdlatul Ulama (NU) mengenai cinta tanah air (nasionalisme) yang digabung sebagai upaya menggabungkan spirit islam dan kebangsaan. Konsep ini lahir sebagai respon atas perlawanan terhadap penjajah.

Pasca Indonesia merdeka, konsep ini bertransformasi menjadi konsep untuk mempertahankan kemerdekaan sebagai bukti kecintaan terhadap tanah air (Ibda, 2017). Hal tersebut bagi Tarekat Shiddiqiyyah dianggap tidak terlalu penting. Yang terpenting adalah substansi dari kaidahnya yaitu mencintai tanah air adalah selaras dengan perintah Nabi. Dalam suatu hadis Nabi bersabda man lam yasykurinnas lam yasykurillah yang berarti barangsiapa yang tidak berterima kasih kepada sesama manusia, maka dia tidak berterima kasih kepada Allah (Mansyur, 2019). Hadits tersebut dimaknai bahwa ketika seseorang mensyukuri perjuangan para leluhur dan para pahlawan dalam upaya memperjuangkan kemerdekaan bangsa Indonesia dalam bentuk mencintai tanah air, maka hal itu berarti dia juga bersyukur kepada Allah. Nasionalisme bagi Tarekat Shiddiqiyyah dimaknai sebagai perwujudan rasa syukur warga kepada Allah.

Dalam lintasan sejarah Islam diketahui bahwa spirit nasionalisme juga ditunjukkan Nabi Muhammad ketika menyikapi tanah air kelahirannya (Makkah) pada saat melakukan hijrah ke Madinah (Irawan, 2018). Bahkan sebelum hijrah sekalipun kecintaan Nabi Muhammad terhadap Makkah diwujudkan dalam bentuk islah (perdamaian) atau perbaikan dalam seluruh tatanan kehidupan kepada masyarakat yang dimulai dari perbaikan akidah, dilanjutkan dengan bimbingan akhlak dalam berkeluarga, bermasyarakat, bernegara, dan seterusnya. Nabi tidak menghendaki saudara-saudaranya sebangsa dan setanah air memiliki tatanan kehidupan yang hancur berantakan.. Nabi juga tidak ingin rakyatnya menjadi rakyat yang tidak sabar, tidak peduli kepada tanah airnya, dan suka membuat kerusuhan (Abdullah, 2017). Sebagai warga negara yang baik harus menumbuhkan jiwa nasionalisme sesuai dengan ajaran Nabi Muhammad.

Penguatan nasionalisme dalam diri Tarekat Shiddiqiyyah juga diwujudkan dalam bentuk hadirnya anjuran dari Kyai Muchtar kepada setiap warga tarekat bahwa mereka harus sanggup memiliki rasa cinta tanah air kepada Negara Kesatuan Republik Indonesia. Bahkan lebih dari itu, Kyai Muchtar mengeluarkan pernyataan bahwa warga Shiddiqiyyah yang tidak sanggup cinta kepada tanah airnya maka mereka bukanlah pengikut Shiddiqiyyah (Tasmuji, 2016). Pandangan Tarekat Shiddiqiyah tentang nasionalisme, tercermin secara kuat pada kesanggupan ke lima yakni bakti kepada Negara Republik Indonesia merupakan titik temu nasionalisme dan agama dalam ajaran Tarekat Shiddiqiyah. Melalui negara hal-hal seperti perlindungan terhadap segenap warga, memajukan kesejahteraan umum, mencerdaskan kehidupan bangsa dan ikut menertibkan dunia, akan bisa direalisasikan. Kewajiban berbakti kepada negara menjadi sesuatu yang sangat penting. Bakti kepada negara merupakan wujud syukur sebagai warga negara. Rasa cinta tanah air harus merupakan sebagian dari iman dan imam yang menjadi pokok pangkal agama (Tedy, 2018). Setiap warga dalam pandangan tarekat ini harus berbakti kepada negara, sebab dengan hadirnya negara dapat mewujudkan tujuan kehidupan berbangsa dan bermasyarakat.

Tarekat Shiddiqiyyah merupakan salah satu aliran tasawuf yang memiliki ajaran tentang nasionalisme. Tarekat ini mencoba menjawab permasalahan kehidupan berbangsa dan bernegara dengan melegitimasi hal tersebut ke dalam ranah sufistik yang menjadikan nasionalisme sebagai 
bagian dari praktik yang dilaksanakan (Tasmuji, 2019). Ajaran nasionalisme secara jelas nampak dari delapan ajaran pokok kesanggupan sebagai warga pengikut Tarekat Shiddiqiyyah. Tanah air dalam pandangan Tarekat Shiddiqiyyah merupakan tempat kedatangan manusia, dan di dalam diri manusia memiliki unsur yang terdiri dari air dan tanah. Adapun tanah adalah tempat manusia berpijak dengan segala hasil buminya yang dapat dimanfaatkan, sementara air sebagai sumber kehidupannya. Warga Tarekat Shiddiqiyyah juga diwajibkan untuk sanggup bakti kepada NKRI. Hal ini memiliki arti bahwa dianjurkan bagi warga tarekat untuk ikut serta dalam melindungi segenap bangsa Indonesia, memajukan kesejahteraan umum, dan ikut serta dalam menertibkan dunia berdasarkan Pancasila dan Undang-Undang Dasar 1945 (Wirdiyana, 2019). Setiap warga Tarekat Shiddiqiyyah diwajibkan untuk sanggup dalam cinta tanah air.

Perasaan cinta tanah air dapat diwujudkan dalam berbagai hal, yaitu (a) menjaga nama baik seluruh bangsa dan tanah air Indonesia, (b) berjiwa dan berkepribadian Indonesia, (c) bangga bertanah air Indonesia menjadi penduduk Indonesia dan bangga dengan adat istiadat yang bermacam-macam, (d) tidak melalukan perbuatan dan tindakan yang merugikan tanah air dan bangsa, dan (e) setia dan taat pada peraturan perundang-undangan yang berlaku (Basri et al., 1997). Konsep nasionalisme dalam Tarekat Shiddiqiyyah diartikan sebagai sikap cinta tanah air. Sikap cinta tanah air ini sudah menjadi poin penting dan diwajibkan bagi semua warga tarekat untuk mengamalkannya. Tarekat Shiddiqiyyah memiliki dua aspek poin yang diajarkan untuk membangun kesadaran berbangsa dan bernegara. Pertama, aspek keimanan yaitu muatan pendidikan keagamaan. Kedua, aspek kebangsaan yaitu pendidikan cinta tanah air. Jiwa nasionalisme dianggap sebagai suatu pemberian untuk warga Tarekat Shiddiqiyyah dari Tuhan dan bukan merupakan suatu ketidaksengajaan. Sebagai wujud rasa syukur terhadap anugerah Tuhan Bagi tarekat ini, kemerdekaan bangsa Indonesia lebih ditonjolkan. Salah satu poin penting dalam pemahaman konsep nasionalisme dari tarekat Șiddīqīyah adalah gagasan mereka tentang tanggal berdirinya Negara Republik Indonesia. Jika mayoritas pendudukan Indonesia saat ini menilai bahwa tanggal deklarasi kemerdekaan Indonesia oleh Ir. Soerkarno merupakan tanggal yang sama dengan tanggal awal terbentuknya Negara Kesatuan Republik Indonesia, namun tidak demikian dengan tarekat Șiddīqīyah. Tarekat ini memiliki pemahaman yang berbeda dengan mayoritas penduduk Indonesia. Baginya tanggal terbentuknya NKRI adalah tanggal 18 Agustus 1945.

Teks proklamasi secara tidak langsung telah menjadi dokumen yang memperingatkan seluruh bangsa Indonesia bahwa yang merdeka saat itu bukanlah negara Indonesia, tetapi bangsa Indonesia. Bangsa tidak sama dengan negara. Bangsa adalah satu kelompok masyarakat yang bersamaan asal keturunan, adat, bahasa maupun sejarah hidup yang sama. Bangsa juga dapat diartikan sebagai golongan manusia, binatang atau tumbuhan yang mempunyai asal-usul dan sifat khas yang sama. Negara adalah satu organisasi dalam suatu wilayah yang mempunyai kekuasaan tertinggi yang sah dan ditaati oleh rakyat. Diartikan juga sebagai satu kelompok sosial yang menduduki wilayah atau daerah tertentu yang terorganisasi di bawah lembaga politik dan pemerintah yang efektif, mempunyai kesatuan politik, berdaulat sehingga berhak menentukan tujuan nasional maupun kepentingannya tersendiri.

Sebagai simbol untuk merepresentasikan jati diri bangsa dan cinta tanah air, Tarekat Shiddiqiyyah mendirikan berbagai monumen di lingkungan pesantren seperti monumen cinta tanah air bagian dari iman, monumen sumpah pemuda, monumen proklamasi kemerdekaan bangsa Indonesia, monumen atas berkat rahmat Allah Yang Maha Kuasa, monumen Garuda Pancasila, dan monumen lagu kebangsaan Indonesia Raya. Selain bangunan monumen, aktifitas ketarekatan juga menjadi bukti perwujudan cinta tanah air, diantaranya menyanyikan lagu Indonesia Raya, dan syair sumber kemerdekaan bangsa Indonesia.

Kuatnya doktrin tentang nasionalisme di kalangan pengikut Tarekat Shiddiqiyyah terjadi disebabkan oleh hubungan emosional antara mursyid dan murid tarekat. Hal ini memberikan pengaruh terhadap proses pembentukan kepribadian dan pola berfikir anggota tarekat. Ikatan emosional yang begitu kuat antara guru dengan murid, menjadikan apapun yang diperintahkan oleh guru dipandang sebagai suatu bentuk anjuran yang harus dilaksanakan. Hubungan antara guru dan murid menurut Dodi (2018) merupakan salah satu fungsi doktrinal tarekat yang berkesinambungan secara menyeluruh 
dengan seluruh ajaran-ajaran tarekat lainnya demi mencapai tujuan akhir yaitu mendekatkan diri kepada Allah untuk mendapatkan keselamatan di dunia dan akhirat.

Upaya Tarekat Shiddiqiyyah untuk menanamkan rasa nasionalisme kepada para pengikut tarekat dan santri yang menimba ilmu di pesantren dilakukan melalui berbagai cara, diantaranya membiasakan pengikut tarekat menyanyikan lagu Indonesia Raya dalam setiap seremoni aktivitas ketarekatan, membaca syair sumber kemerdekaan bangsa Indonesia pada acara-acara tertentu dan biasanya dibacakan setelah lagu kebangsaan Indonesia Raya dikumandangkan. Bentuk perilaku cinta tanah air yang lain adalah mengikuti peringatan dan perayaan proklamasi kemerdekaan Republik Indonesia, mengikuti peringatan hari Sumpah Pemuda setiap tanggal 28 Oktober. Kemudian untuk penguatan penyebaran pemahaman ini, Tarekat Shiddiqiyyah menginisiasi pendiri Persaudaraan Cinta Tanah Air (PCTA) yang keanggotaannya bukan saja dari kalangan pengikut Tarekat Shiddiqiyyah tetapi juga umat Islam yang lain bahkan dari masyarakat luas yang berbeda agama dan budaya. Melalui pendidikan cinta tanah air di pesantren maka terjadilah titik temu antara nasionalisme dan agama dalam Tarekat Shiddiqiyyah sehingga rasa nasionalisme dibingkai dengan nilai-nilai agama dalam harmoni yang indah, yang dapat digunakan sebagai alternatif dalam menanamkan rasa cinta tanah air di kalangan masyarakat.

\section{SIMPULAN}

Tarekat Shiddiqiyyah berkembang sangat pesat di Indonesia. Tarekat ini mempunyai kekhasan tersendiri yang berbeda dengan kelompok sufi atau tarekat yang lain. Tarekat Shiddiqiyyah meyakini bahwa nasionalisme bukan hanya urusan warga negara, tetapi perintah agama. Bentukbentuk nasionalisme tarekat shiddiqiyyah yaitu (1) delapan kesanggupan yang harus dipegang teguh mulai dari kesanggupan berbakti kepada Allah, Rasul, sesama manusia, negara sampai menghargai waktu, (2) monumen kebangsaan sebagai media pendidikan cinta tanah air Indonesia bagi generasi muda, (3) syair sumber kemerdekaan Bangsa Indonesia dan berdirinya Negara Kesatuan Republik Indonesia, serta (4) pendirian persaudaraan cinta tanah air Indonesia yang diharapkan dapat membangkitkan kembali rasa cinta tanah air bangsa Indonesia melalui seni, budaya, pendidikan dan pemberdayaan ekonomi.
Titik temu agama dan nasionalisme dalam tarekat shiddiqiyyah yaitu adanya konsep hubbul wathan minal iman yang berarti cinta tanah air adalah sebagian dari iman. Melalui pendidikan cinta tanah air di pesantren maka terjadilah titik temu antara nasionalisme dan agama dalam Tarekat Shiddiqiyyah sehingga rasa nasionalisme yang dibingkai dengan nilai-nilai agama dalam harmoni yang indah.

\section{DAFTAR RUJUKAN}

A'dham, S. (2011). Etos Ekonomi Kaum Tarekat Shiddiqiyyah. Al-Iqtishad. Jurnal Ilmu Ekonomi Syariah, 3(2), 313-330.

Abdullah, M. (2017). Kontribusi Nilai-Nilai Keimanan dan Kemanusiaan Persaudaraan Cinta Tanah Air Indonesia. TEOSOFI: Jurnal Tasawuf dan Pemikiran Islam, 7(1), 249-272.

Arif, S. (2016). Pandangan dan Perjuangan Ideologis Hizbut Tahrir Indonesia (HTI) dalam Sistem Kenegaraan di Indonesia. Aspirasi: Jurnal Masalah-masalah Sosial, 7(1), 93-104.

Basri, Y, et al., (1997). Pendidikan Pancasila dan Kewarganegaraan Sekolah Lanjutan Tingkat Pertama untuk Siswa Kelas 1. Jakarta: Balai Pustaka.

Azizah, N. (2019). Islamisme: Ideologi Gerakan Kahar Mudzakkar di Sulawesi Selatan 1952-1965. Jurnal Penelitian Keislaman, 15(2), 95-104.

Dhofier, Z. (1994). Tradisi pesantren: Studi tentang pandangan hidup kyai. Jakarta: LP3ES.

Dodi, L. (2018). Antara Spiritualitas dan Realitas Tarekat Shiddiqiyyah dalam Bingkai Fenomenologi Annemarie Schimmel. Prosiding Nasional, 1, 29-54.

Ibda, H. (2017). Relasi Nilai Nasionalisme dan Konsep Hubbul Wathan Minal Iman dalam

Pendidikan Islam. International Journal Ihya "Ulum al-Din, 19(2), 245-270.

Irawan, D. (2018). Nilai-Nilai Pendidikan Islam dalam Kesenian Rodat Al-Fajar Didukuh Kiringan, Canden, Sambi, Boyolali (Skripsi). Surakarta: IAIN Surakarta.

Jailani, I. A. (2015). Pergolakan Politik Antara Tokoh Muslim dan Nasionalis pada Saat Penentuan Dasar Negara Republik Indonesia. KARSA: Journal of Social and Islamic Culture, 22(2), 246-259.

Munir, M. (2012). Rasionalitas dan Makna 
Harta (Studi Fenomenologi pada Tarekat Shiddiqiyyah Jombang) (Disertasi). Malang: Universitas Brawijaya.

Nasih, A. M. (2016). Sepenggal Perjalanan Hidup Sang Mursyid Kyai Muhammad Mucchtar bin Haji Abdul Mu'thi. Jombang: Al Kautsar Dhibra.

Pranoto. (2015). Sejarah Thoriqoh Shiddiqiyyah Fase Pertama: Kelahiran Kembali Nama Thoriqoh Shiddiqiyyah. Jombang: ORSHID. Shodiq, M. (2016). Thariqoh Shiddiqiyah di Tengah Masyarakat Urban Surabaya. Surabaya: Pustaka Idea.

Sukmadinata, N.S. (2011). Metode Penelitian Pendidikan. Bandung. Remaja: Rosadakarya.

Supyan, M. D. (2016). Gerakan Darul Islam (DI) SM Kartosuwirjo di Jawa Barat Dalam Mewujudkan Negara Islam Indonesia (NII) (1945-1962 M) (Tesis). Yogyakarta: UIN Sunan Kalijaga Yogyakarta.

Syakur, A. (2008). Gerakan Kebangsaan Kaum Tarekat: Studi Kasus Tarekat Shiddiqiyah Pusat Losari, Ploso, Jombang Tahun 19752006. Yogyakarta: UIN Sunan Kalijaga.
Tasmuji, T. (2016). Nasionalisme Sufistik dalam Tarekat Șiddīqīyah di Ploso Jombang. TEOSOFI: Jurnal Tasawuf dan Pemikiran Islam, 6(2), 404-434.

Tasmuji, T. (2019). Sufisme dan Nasionalisme: Studi tentang Ajaran Cinta Tanah Air dalam Tarekat Siddīqīyah di Ploso (Disertasi). Jombang: UIN Sunan Ampel Surabaya.

Tedy, A. (2018). Tarekat Mu'tabaroh di Indonesia (Studi Tarekat Shiddiqiyyah dan Ajarannya). El-Afkar: Jurnal Pemikiran Keislaman dan Tafsir Hadis, 6(1), 31-42.

Turmudi, E. (2004). Perselingkuhan Kiai dan Kekuasaan. Yogyakarta: PT LKiS Pelangi Aksara.

Wirdiyana, F. (2019). Pandangan Pelaku Tarekat Siddiqiyah Terhadap Ideologi Negara Hizbut Tahrir Indonesia (HTI) (Skripsi). Surabaya: UIN Sunan Ampel Surabaya.

Zaprulkhan, Z. (2014). Relasi Agama dan Negara dalam Perspektif Islam. Walisongo: Jurnal Penelitian Sosial Keagamaan, 22(1), 105-132. 